\title{
Team Building as a Tool to Strengthen the Company's Position in the Market
}

\author{
Lyudmila Aleksandrovna Saenko ${ }^{1 *}$, Tatiana Ivanovna Barsukova ${ }^{1}$, Elena Vasilyevna Khokhlova ${ }^{2}$, Valentina Ana- \\ tolyevna Ivashova ${ }^{2}$, Diana Sergeevna Kenina ${ }^{2}$ \\ ${ }^{I}$ North Caucasus Social Institute, Goleneva Str. 59A, Stavropol, 355012, Russia \\ ${ }^{2}$ Stavropol State Agrarian University, Zootechnical per. 12, Stavropol, 355017, Russia \\ *Corresponding author E-mail: saenko.l.a@bk.ru
}

\begin{abstract}
The article considers the concept of team, team roles according to M. Belbin, factors affecting team building, team building model aimed at improving the quality of professional training of higher school graduates. Also, an analysis of the research of Russian scientists, the content analysis of the search service "Yandex" on request was conducted: team formation, team building tools, team building scenarios, grouping of factors affecting the process of team building. Official statistics, official fertility rates and the liquidation rate of enterprises in the Russian Federation were analyzed. The interaction between the model of organizational behavior and the model of teambuilding is considered. An effective model of teambuilding in educational organizations was developed, which allows developing such qualities among students as: stress-resistance, sociability, creativity, ability to work in a team.
\end{abstract}

Keywords: team, team roles, team building, effective team building model.

\section{Problem Statement}

The unstable social and economic situation forces enterprises to adjust the methods of personnel management, which requires employees to adapt more quickly to the changing conditions of production. Team building at the enterprise is one of the modern and effective methods that help in the adaptation and building of an effective team. Professional training of a University graduate should meet the needs of modern production.

\subsection{Analysis of Previous Studies}

R. L. Krichevsky and E. M. Dubovskaya summarized the research of Russian and American scientists and identified several features of the team: 1) shared vision; 2) complementarity of functions in the distribution of roles between team members; 3) ability to quickly respond to changes; 4) mutual understanding in the team; $5)$ ability to motivate team members $[1,2,3]$.

Undoubtedly, the team in the organization is a single mechanism that ensures effective work, each team member has a role, there are many opinions about how team roles should be distributed, one of such theories is the theory of M. Belbin $[4,5,6]$.

The theory of nine roles by Meredith Balbin clearly articulates and distributes team roles: from an idea generator, resources' researcher, to a motivator and inspirer of the team, a coordinator, an analysist, an implementer, a specialist, and a controller.

The emergence of the concept of "team building", and the evolution of this term is largely due to the emphasis on the features of psycho-emotional behavior of employees and their motivation to achieve professional goals.

At present, a new economic and management thinking has been formed, human resource has started to be considered as the main resource of companies $[3,5]$.
Along with other methods of personnel management, team building tools allow to solve the problems of the team much faster and more efficiently.

The content analysis of one of the popular search services "Yandex" proves the relevance of this tool.

At requests: teambuilding, teambuilding tools, teambuilding scenarios, the following results were obtained:

- team building -4 million;

- team building tools -29 million;

- team building scenarios - 13 million.

The process of team building is influenced by many factors, including, first of all, the employees themselves with their psychological characteristics, personal and professional goals, as well as motivation.

The leader of the organization has a great influence on the process of team building, implementing his leadership functions, using his leadership style.

Close-knit team and the implementation of all tasks, creates a positive image of the organization.

\subsection{Purpose of Work}

Substantiation of the problem and development of fundamentally new approaches to the formation of professional competence of future specialists, taking into account the need for team solving production tasks.

\section{Materials and Methods}

The research methods are the analysis and generalization of researchers ' ideas about possible models of team building and the experience of implementing such models in the training of a graduate of higher school in Russia. 


\subsection{Presentation of the Main Research Materials}

According to official statistics by the end of 2017 in the Russian Federation, the ratio of the official liquidation of companies made 135,3 , while the ratio of official "set up" of enterprises amounted to 91.3 ,the following statistics are based on the data of 1,000 companies, in 2015, however, this ratio amounted to 102,7 .We believe one of the reasons for this situation is an uncertain position of companies in the market. Most organizations assign one of the last roles to the implementation of team building tools, which are a powerful instrument for social-economic development of the team. The analysis of the scientific community's ideas about modern models of team building and their dependence on the accepted models of organizational behavior determines the directions of improving the professional training of graduates of higher school, capable of implementing team production tasks and ensuring the effectiveness of production activities.

The key components of the interaction between the organizational behavior model and the team building model are the following mechanisms (Fig. 1):

- Legal and regulatory requirement to the organizational behavior of the staff;

- Informative-content informing of the personnel about the requirements to organizational behavior;

- Psychological-formation of positive attitudes of staff to meet new requirements of behavioral and motivational components;

- Training- educational program for the introduction to the model of organizational behavior;

- Financial-differentiation in wages.

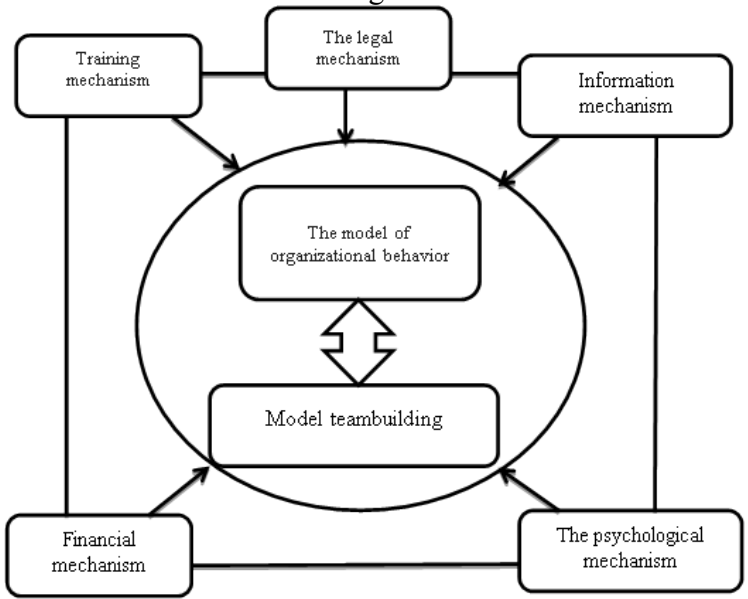

Fig. 1: Interaction of organizational behavior model and team building model

One of the main forms of team building that organizations implement in practice are trainings.

Despite the large variety of specific exercises, techniques and styles used in training work, it is customary to distinguish several basic training methods. These traditionally include a group discussion and situation-role games, in which there is an opportunity to unlock the potential of the employee and to determine the key motivating factors.

It is important to organize the implementation of motivating and team-building activities at the stage of professional development of the future specialist in the University $[7,8,9]$.

In the practice of leading universities of the country a set of teambuilding activities is implemented. Including Stavropol Territory, where such experience is available. In particular, it is available in Stavropol State Agrarian University and North Caucasus Federal University.

In Stavropol State Agrarian University such a team-building event is represented by the project "Trajectory of growth", which in the last three years has acquired an educational orientation, although its implementation is carried out by the student asset of the Uni- versity. The main activities were rope course, patriotic events and preparing and defending of a socially significant project (Fig. 2).

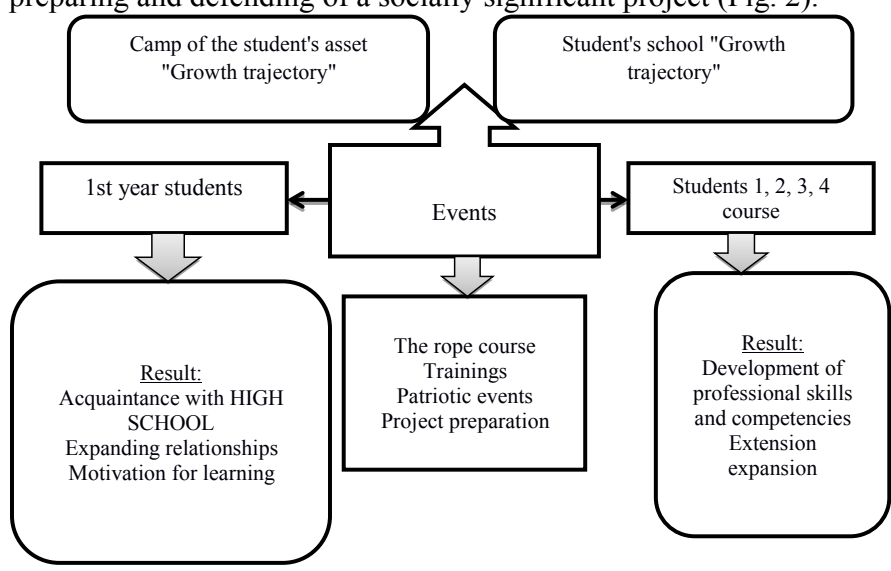

Fig. 2: Model of realization of the project "Trajectory of growth" in Stavropol SAU

On average, already in the first year of study more than $45.6 \%$ of students show their active position, a brand team building event is the project "Growth trajectory", which has acquired an educational focus the last three years, the main activities were the rope course, patriotic events and the preparing and defending of a socially significant project, the results of the project is a significant social effect, first of all, is the expansion of communication in the student environment, beyond the academic groups, as well as the adaptation of first-year students to new conditions, and the development of new competencies in senior students.

The whole program of activities of the school of student activists is thought out and implemented by the students of the University, which is also an important component of team building $[10,11]$. The most highly appreciated parts of the program "Trajectory of growth StSAU-2017" were the first aid quest "Save life" (9.8 points), evening events from the Art-Directorate (9.5 points), the game for team building (9.3 points). Public defense of projects, role-playing game on defending of projects, master classes and lectures, in this regard, in 2017-2018, the University implemented the project "the Corps of trainers", thanks to which it was possible to strengthen the staff of "trainers" by competent students of the University.

Educational institutions shape the personality of future employees of companies, which actualizes the need for team building activities and the introduction of effective team building models (Fig. 3) $[12,13,14]$

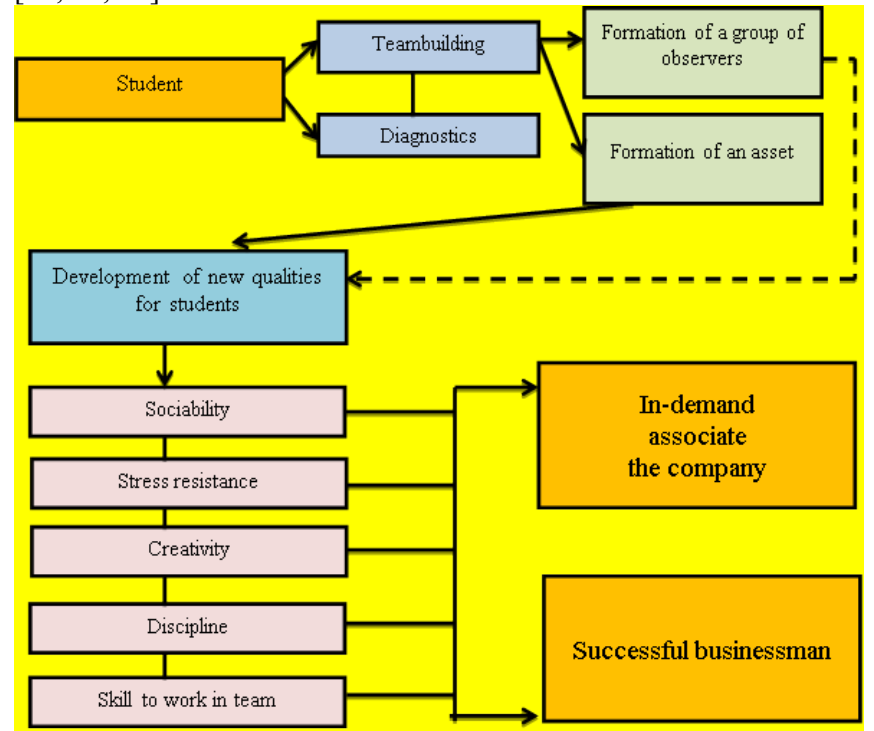

Fig. 3: Effective model of team building in educational institutions 


\section{Discussion}

Thus, according to the results of the study, an effective model of team building in educational institutions was developed, thanks to which students developed useful qualities: stress resistance, communication skills, creativity, ability to work in a team. Graduates of the University with such qualities receive an advantage in the employment process and more opportunities to become successful businessmen $[15,16,17,18]$.

\section{Conclusion}

The results of the study determine the areas of improving the training of managers, specialists of municipal and regional management. The vector of scientific search of actual resources of professional training in higher school can be directed on studying of mechanisms of increase of level of social responsibility and leadership qualities of the graduate.

\section{References}

[1] Krichevsky RL \& Dubovskaya EM (2001), Social psychology of a small group: manual for high schools. Moscow. http//peedlib.ru

[2] Lacerenza CN, Marlow SL, Tannenbaum SI, Salas E (2018), Team development interventions: Evidence-based approaches for improving teamwork. American Psychologist, 73(4), 517-531.

[3] Brock SE, McAliney PJ, Ma CH, Sen A (2017), Toward more practical measurement of teamwork skills. Journal of Workplace Learning, 29(2), 124-133.

[4] Krutikov VK, Shelenkova IA. Modern approaches to the management of a successful team. Bulletin of the educational consortium Central Russian University. Economics and management, 7, 114114.

[5] Walsh A, Moore A, Everson J \& DeCaire K (2018), Gathering, strategizing, motivating and celebrating: The team huddle in a teaching general practice. Education for Primary Care, 29(2), 9499.

[6] Chen J, Bamberger PA, Song Y, Vashdi DR (2018), The effects of team reflexivity on psychological well-being in manufacturing teams. Journal of Applied Psychology, 103(4), 443-462.

[7] Stephens M \& Ormandy P (2018), Extending conceptual understanding: How interprofessional education influences affective domain development. Journal of Interprofessional Care, 32(3), 348357.

[8] Chen YC, Liu TF (2018), Constructing management competencerelated weights in the human resources field in hi-tech industry with the leadership life cycle theory. Journal of Quality, 25(2), 120-140.

[9] Levasseur RE (2017), People skills: Building the perfect team-a change management perspective. Interfaces, 47(3), 270-272.

[10] Jing L, Li J \& Cao J (2017), Strengthening the construction of student cadres based on 360 degree feedback evaluation. Technical Bulletin, 55(4), 16-21.

[11] Forrest CK \& Bruner MW (2017), Evaluating social media as a platform for delivering a team-building exercise intervention: A pilot study. International Journal of Sport and Exercise Psychology, 15(2), 190-206.

[12] Fujita T, Ogushi K, Ishibashi H, Koike Y \& Horimoto Y (2017), Current status of team building through newcomer employee education by on the job training: Influence of utilizing "OJT SHEET" on newcomer employee education. Rigakuryoho Kagaku, 32(6), 803808.

[13] Spittka J (2016), Team development: It depends on communication. Deutsches Arzteblatt International, 113(29-30), 2-3.

[14] Caballé S \& Clarisó R (2016), Formative Assessment, Learning Data Analytics and Gamification: In ICT Education, 1-359.

[15] Lykourentzou I, Kraut RE, Wang S \& Dow SP (2016), Team dating: A self-organized team formation strategy for collaborative crowdsourcing. Conference on Human Factors in Computing Systems - Proceedings, 1243-1249.

[16] Nirschl F, Fuchs M, Dorn JA \& McDonnell JJ (2016), Quantitative competence model for e-recruiting and team building in safety critical domains. IEEE International Technology Management Conference, Science, 352(6283), 378.
[17] Lohani M, Stokes C, McCoy M, Bailey CA \& Rivers SE (2016), Social interaction moderates human-robot trust-reliance relationship and improves stress coping. ACM/IEEE International Conference on Human-Robot Interaction, 471-472.

[18] Fieldsend-Danks P (2016), The dialogues project: Students as partners in developing research-engaged learning. Art, Design and Communication in Higher Education, 15(1), 89-102. 